\title{
INVESTIGATION OF EFFECTS OF THE SOUTHERN WIND ON STOCK EXCHANGES
}

\author{
DOI: 10.17261/Pressacademia.2021.1533 \\ PAP- V.14-2021(55)-p.180-181
}

\section{Yusuf Polat}

Aksaray University, Faculty of Economics and Administrative Sciences, Department of Accounting-Finance, Aksaray, Turkey. yusufpolat@aksaray.edu.tr, ORCID: 0000-0002-2255-0658

\section{To cite this document}

Polat, Y., (2021). Investigation of effects of the Southern wind on stock exchanges. PressAcademia Procedia (PAP), $14,180-181$.

Permanent link to this document: http://doi.org/10.17261/Pressacademia.2021.1533

Copyright: Published by PressAcademia and limited licensed re-use rights only.

\section{ABSTRACT}

Purpose- In the field of behavioral finance and economics, individuals' cognitive ease and strain have been studied in relation to anomalies and cognitive reflection, and therefore rationality. It is observed that meteorological factors related to these phenomena create significant differences in transaction volumes and behaviors in individuals on the basis of rationality. In the geography of Istanbul, the relevance of a phenomenon coming from the past and applied in the Eastern Roman (Byzantine) and Ottoman Empire constitutes the research problem of this study. It is known that in the past, during the Byzantine and Ottoman Empire periods, when the southwestern wind blows in Istanbul, the fish lost their way and became silly, and the cases were postponed considering the danger that the magistrates could make irrational decisions due to the comforting and relaxing effect of the wind. It is aimed to investigate the effects of this situation on BIST-100 within the scope of cognitive comfort and cognitive strain.

Methodology- The correlation between the minimum 5-year data on the stock market and the meteorological data for the same period will be tried to be examined. There are several difficulties with this application. First of all, meteorological data and data known to affect the stock market should be separated from each other and their effects should be isolated.

Findings- Obtaining data on the effects of phenomena such as cognitive ease and loss aversion on individuals' psychic states, and determining their effects on transaction volume and aggressive behavior.

Conclusion- It is expected that some meteorological changes may affect the cognitive reflection levels of individuals, causing investment and saving behaviors to move away from rationality, and wind as well as sunny-cloudy days may be effective on this behavior.

Keywords: Anomalies, cognitive ease, wind power.

JEL Codes: G10, G20, G23

\section{LODOS RÜZGÂRININ BORSA ÜZERINDEKI ETKILERININ INCELENMESi}

\section{ÖZET}

Amaç- Davranışsal finans ve iktisat alanında bireylerin bilişsel rahatlık ve bilişsel gerginlikleri anomaliler ve bilişsel yansıma konularıyla, dolayısıyla rasyonalite ile ilintili olarak işlenegelmiştir. Söz konusu fenomenlere ilişkin meteorolojik etmenlerin yine bireylerde rasyonalite temelinde işlem hacimlerinde ve davranışlarında anlamlı farklııklar oluşturdukları gözlemlenmiş olgular olarak karşımıza çıkmaktadır. İstanbul coğrafyasında ise geçmişten gelen ve Doğu Roma (Bizans) ile Osmanlı Devletinde uygulanagelen bir fenomenin konuyla ilintisi bu çalışmanın araștırma problemini oluşturmaktadır. Geçmişte Bizans ve Osmanlı Devleti dönemlerinde İstanbul'da lodos rüzgârının (güneybatı rüzgârı) estiği zamanlarda balıkların yönlerini kaybedip şapşallaştıkları, sulh yargıçlarının rüzgârın rahatlatıcı ve gevşetici etkisi nedeniyle rasyonel olmayan kararlar verebilme tehlikesi göz önünde bulundurularak davaların ertelendiği bilinmektedir. Söz konusu durumun bilişsel rahatlık ve bilişsel gerginlik kapsamında BiST-100 üzerindeki etkilerinin araştıııması hedeflenmektedir.

Yöntem- Borsaya ilişkin asgari 5 yıllık veriler ile aynı döneme ilişkin meteorolojik veriler arasında korelasyon incelenmeye çalıșılacaktır. Söz konusu uygulamaya ilişkin çeşitli zorluklar bulunmaktadır. Öncelikle meteorolojik veriler ile borsayı etkilediği bilinen verilerin birbirinden ayıklanması ve etkilerinin izole edilmesi gerekmektedir.

Bulgular- Bilişsel rahatlık ve kayıptan kaçınma gibi fenomenlerin bireylerin psişik durumlarını etkilediğine ilişkin veriler elde edilerek bunların işlem hacmi ve agresif davranışlardaki etkilerinin tespit edilmesi.

Sonuç- Birtakım meteorolojik değişiklerin bireylerin bilişsel yansıma düzeylerini etkileyerek yatırım ve tasarruf davranışlarının rasyonaliteden uzaklaşmasına neden olabileceği ve güneşli-bulutlu günlerin yanı sıra rüzgârın bu davranış üzerinde etkili olabileceği beklenmektedir.

Anahtar Kelimeler: Anomaliler, bilişsel rahatlık, rüzgâr gücü.

JEL Kodları: G10, G20, G23 


\section{REFERENCES}

Akerlof, G. A.; Shiller, R. J. (2018). Hayvansal Güdüler: İnsan Psikolojisi Ekonomiyi Nasıl Yönlendirir ve Küresel Kapitalizm Için Niçin Önemlidir. Scala Yayıncılık.

Akerlof, G. A.; Shiller, R. J. (2018). Sazan Avı: Manipülasyonlar ve Hile Ekonomisi.

Cao, G., Xu, W., \& Guo, Y. (2015). Effects of climatic events on the Chinese stock market: applying event analysis. Natural Hazards, 77(3), 1979-1992.

Dowling, M.; Brain, M. L. (2002). Weather, Biorhythms and Stock Returns: Some Preliminary Irish Evidence, Working Paper, December, University of Dublin.

Elster, J. (2006). Ekşi Üzümler: Rasyonalitenin Altüst Edilmesi Üzerine Çalışmalar. Metis.

Floros, C. (2011). On the relationship between weather and stock market returns. Studies in Economics and Finance.

Kahneman, D. (2017). Hızlı ve Yavaş Düşünme. Varlık Yayınları.

Kahneman, D., \& Smith, V. (2002). Foundations of behavioral and experimental economics. Nobel Prize in Economics Documents, 1(7).

Kahneman, D.; Slovic, S. P.; Slovic, P.; Tversky, A. (Eds.). (1982). Judgment under uncertainty: Heuristics and biases. Cambridge university press.

Kahneman, D.; Tversky, A. (2013). Prospect theory: An analysis of decision under risk. In Handbook of the fundamentals of financial decision making: Part I (pp. 99-127).

Kırmızıaltın, E. (2017). İktisat ve Rasyonalite. Heretik Yayınları

Kindleberger, C. P.; Aliber, R. Z. (2013). Çılgınlık, Panik ve Çöküş: Finansal Krizler Tarihi. Türkiye İş Bankası Kültür Yayınları

Mackay, C; De La Vega, J. (2017). Olağanüstü Kitlesel Yanılgılar ve Kalabalıkların Çılgınlığı \& Karışıklığın Karmaşası. Scala Yayıncılık

Magno, A. M. (2021) Paranın İcadı: Finans İtalyanca Konuşurken. Tellekt

Thaler, R. H. (2019). Akılı İnsanların Mantıksız Kararları. Pegasus Yayınları

Thaler, R. H.; Sustein, C. R. (2013). Dürtme (Nudge). Pegasus Yayınları

Tufan, E.; Hamarat, B. (2004). Do cloudy days affect stock exchange returns: Evidence from Istanbul stock exchange. Journal of Naval Science and Engineering, 2(1), 117-126.

Worthington, A. (2009). An empirical note on weather effects in the Australian stock market. Economic Papers: A journal of applied economics and policy, 28(2), 148-154.

Yılmaz, F. (2009). Rasyonalite: İktisat Özelinde Bir Tartışma. Paradigma Yayıncılık 